1 Table S1: UW HSRL Transmitter Specifications

\begin{tabular}{|l|l|}
\hline Parameter & Value \\
\hline Wavelength & $532 \mathrm{~nm}$ \\
\hline Pulse Repetition Rate & $4 \mathrm{KHz}$ \\
\hline Average Power & $0.25 \mathrm{~W}$ \\
\hline
\end{tabular}


3 Table S2: Limits of detection (LOD) of water-soluble ions and elements. Species are divided 4 based on analysis (IC: adipate to $\mathrm{SO}_{4}{ }^{2-}$ in $\mathrm{ppb}$; ICP-QQQ: $\mathrm{Ag}$ to $\mathrm{Zr}$ in ppt).

5

\begin{tabular}{|c|c|c|c|}
\hline IC & LOD & ICP-QQQ & LOD \\
\hline adipate & 22.655 & Ag & 0.743 \\
\hline $\mathrm{NH}_{4}{ }^{+}$ & 42.434 & Al & 29.474 \\
\hline $\mathrm{Ca}^{2+}$ & 45.229 & As & 7.945 \\
\hline $\mathrm{Cl}^{-}$ & 2.144 & $\mathbf{B a}$ & 3.698 \\
\hline DMA & 52.709 & Cd & 4.194 \\
\hline $\mathbf{M g}^{2+}$ & 36.925 & Co & 0.722 \\
\hline maleate & 6.970 & $\mathrm{Cr}$ & 1.150 \\
\hline MSA & 12.316 & Cs & 0.733 \\
\hline $\mathrm{NO}_{3}^{-}$ & 8.917 & $\mathbf{C u}$ & 1.127 \\
\hline oxalate & 12.312 & $\mathbf{F e}$ & 1.191 \\
\hline phthalate & 20.685 & Hf & 0.963 \\
\hline $\mathbf{N a}^{+}$ & 43.476 & $\mathbf{K}$ & 10.480 \\
\hline succinate & 11.046 & Mn & 1.624 \\
\hline \multirow[t]{14}{*}{$\mathrm{SO}_{4}{ }^{2-}$} & 11.982 & Mo & 2.258 \\
\hline & & $\mathbf{N b}$ & 0.522 \\
\hline & & $\mathrm{Ni}$ & 2.837 \\
\hline & & $\mathbf{P b}$ & 0.503 \\
\hline & & $\mathbf{R b}$ & 1.566 \\
\hline & & Se & 82.393 \\
\hline & & Sn & 1.772 \\
\hline & & $\mathrm{Sr}$ & 1.102 \\
\hline & & $\mathbf{T i}$ & 39.046 \\
\hline & & $\mathbf{T l}$ & 0.383 \\
\hline & & V & 1.353 \\
\hline & & $\mathbf{Y}$ & 0.523 \\
\hline & & Zn & 5.880 \\
\hline & & $\mathbf{Z r}$ & 1.008 \\
\hline
\end{tabular}


7 Table S3: Assigned values of $\kappa$ and density ( $\rho$ ) for pure compounds used in the hygroscopicity 8 analysis. Organics refer to those not measured by IC. (a: Almeida et al. (2019) and references 9 therein; b: Drozd et al. (2014); c: Hersey et al. (2013); d: Pöschl et al. (2019); e: Dusek et al. 10 (2010); f: Rose et al. (2010); g: Laborde et al. (2012); and h: Aldhaif et al. (2018)).

11

\begin{tabular}{|c|c|c|}
\hline Species & $\kappa$ & $\rho\left(\mathrm{g} \mathrm{cm}^{-3}\right)$ \\
\hline$\left(\mathrm{NH}_{4}\right)_{2} \mathrm{SO}_{4}$ & $0.61^{\mathrm{a}}$ & 1.77 \\
\hline $\mathrm{K}_{2} \mathrm{SO}_{4}$ & $0.69^{a}$ & 2.66 \\
\hline $\mathrm{Mg}\left(\mathrm{NO}_{3}\right)_{2}$ & $0.63^{\mathrm{a}}$ & 2.30 \\
\hline $\mathrm{NaNO}_{3}$ & $0.87^{\mathrm{a}}$ & 2.26 \\
\hline $\mathrm{Na}_{2} \mathrm{SO}_{4}$ & $0.76^{a}$ & 2.66 \\
\hline $\mathrm{CaCl}_{2}$ & $0.78^{a}$ & 2.15 \\
\hline $\mathbf{M g C l}_{2}$ & $0.98^{a}$ & 2.32 \\
\hline $\mathrm{Ca}\left(\mathrm{NO}_{3}\right)_{2}$ & $1.10^{\mathrm{a}}$ & 2.50 \\
\hline $\mathrm{Ca}_{2} \mathrm{SO}_{4}$ & $0.00^{\mathrm{a}}$ & 2.32 \\
\hline $\mathrm{MgSO}_{4}$ & $0.24^{\mathrm{a}}$ & 2.66 \\
\hline $\mathrm{Na}_{2} \mathrm{Oxalate}$ & $0.68^{b}$ & 2.34 \\
\hline CaOxalate & $0.02^{b}$ & 2.12 \\
\hline MgOxalate & $0.05^{b}$ & 2.45 \\
\hline ZnOxalate & $0.02^{b}$ & 2.56 \\
\hline $\mathrm{NaCl}$ & $1.24^{\mathrm{a}}$ & 2.16 \\
\hline organics & $0.10^{\mathrm{c}, \mathrm{d}, \mathrm{e}}$ & $1.40^{\mathrm{h}}$ \\
\hline black carbon & $0.00^{\mathrm{f}, \mathrm{g}}$ & $2.00^{\mathrm{h}}$ \\
\hline
\end{tabular}




\section{Metro Manila}
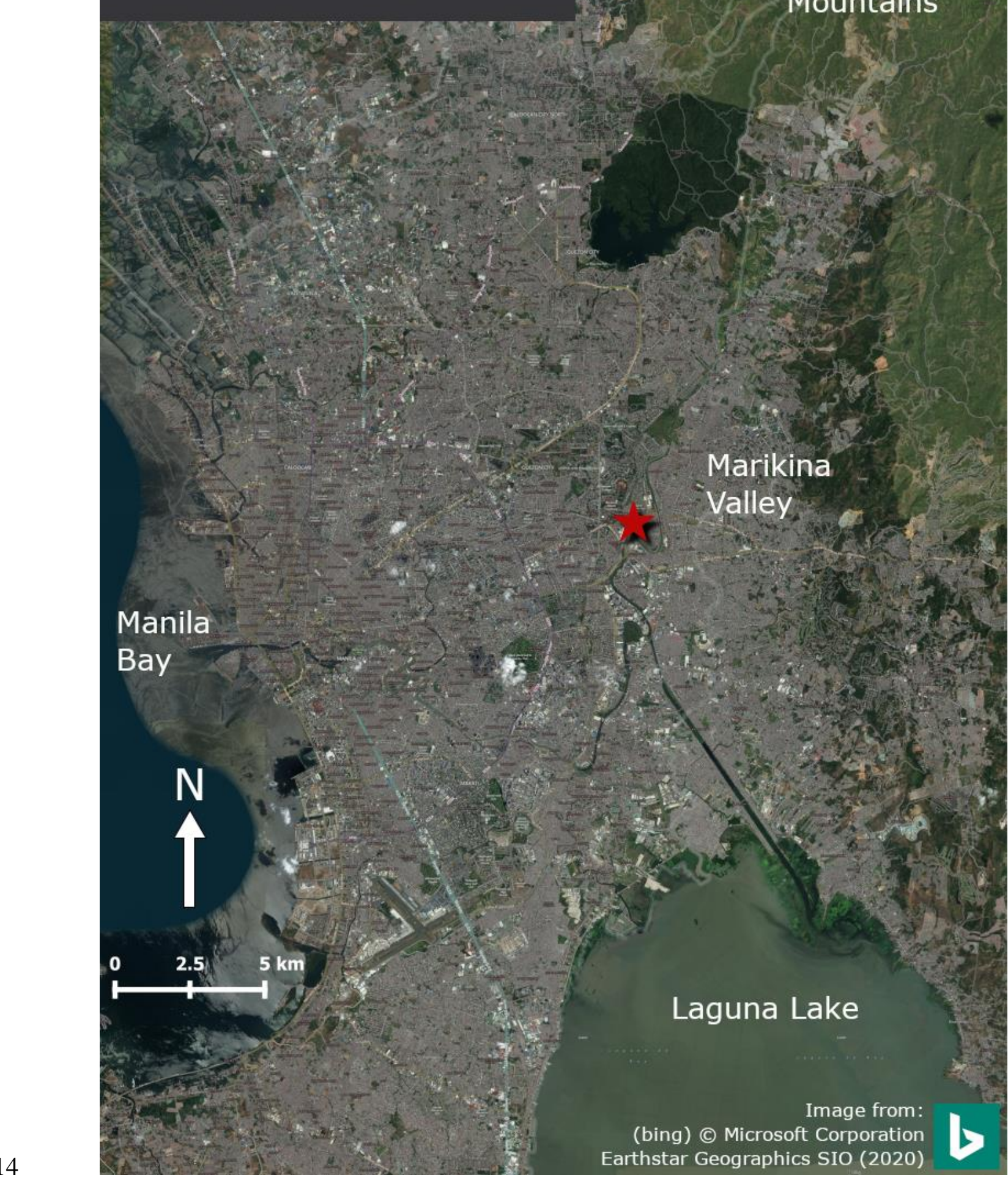

15 Figure S1: Manila Observatory, Quezon City (red star) is within the heavily urbanized areas

16 (gray) in and around Metro Manila, Philippines. It is located west of the Marikina Valley,

17 southwest of the Sierra Madre Mountains, east of Manila Bay, and north of Laguna Lake. 


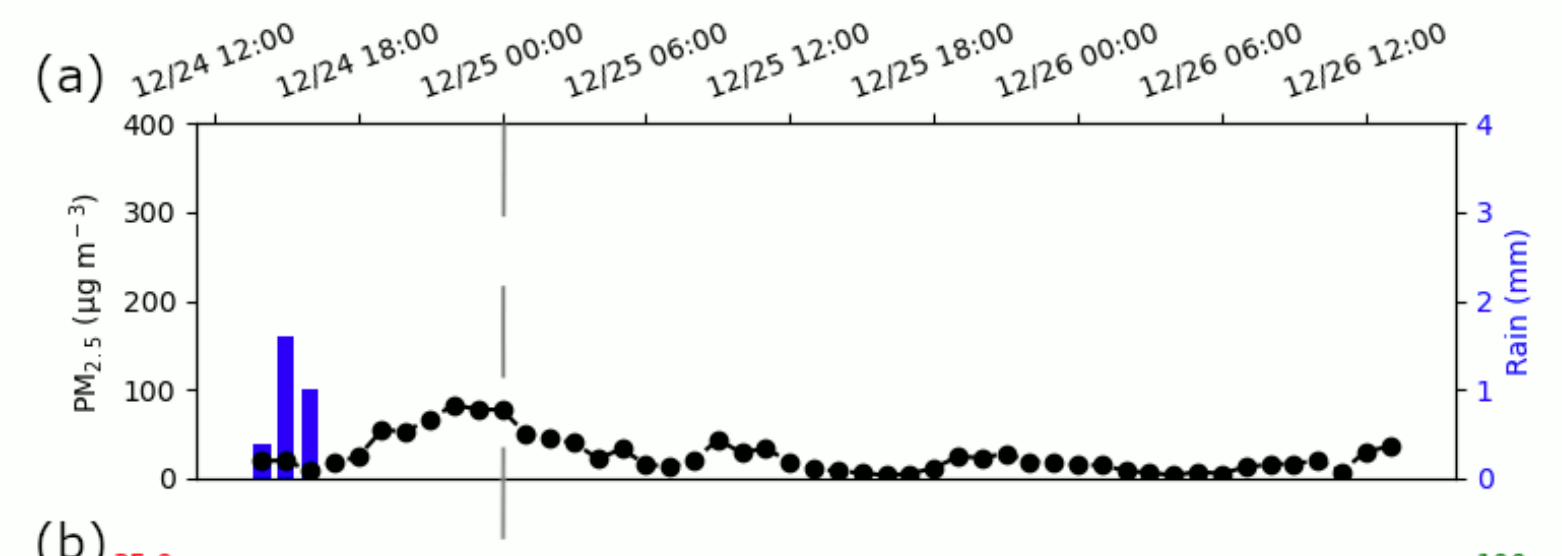

(b)

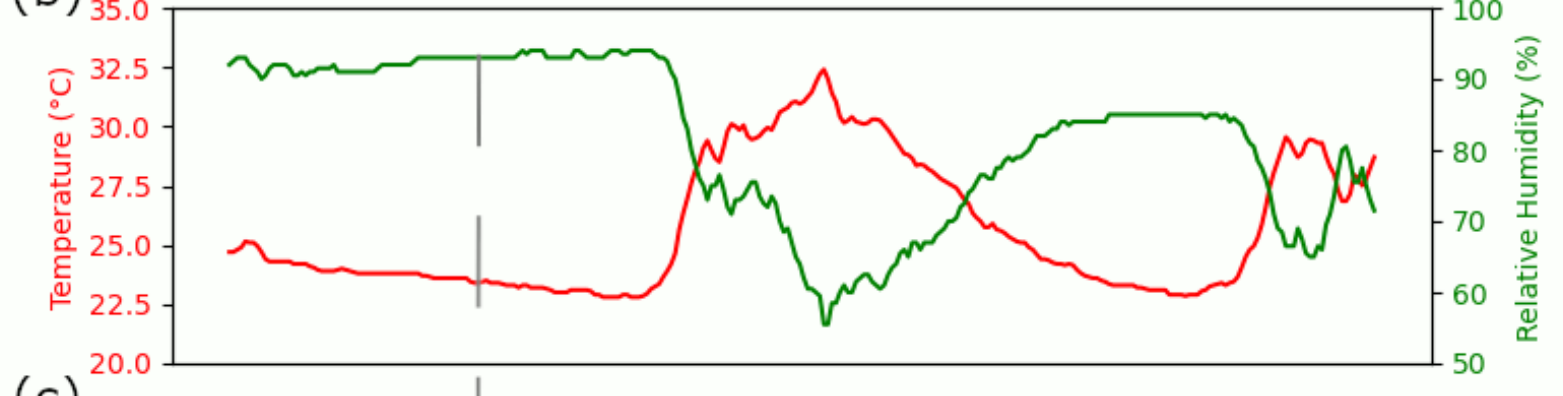

19 Figure S2: (a) $\mathrm{PM}_{2.5}$ mass concentrations and rain accumulation at hourly resolution as measured

20 at the Manila Observatory before the firework event (local time, dashed vertical line indicates 21 midnight). Ten-minute averaged values of (b) temperature and relative humidity, in addition to (c) 22 wind speed and direction. The wind barb legend in (c) shows how flags are added to the staff with 23 increasing wind speed and in the direction where the wind comes from. 


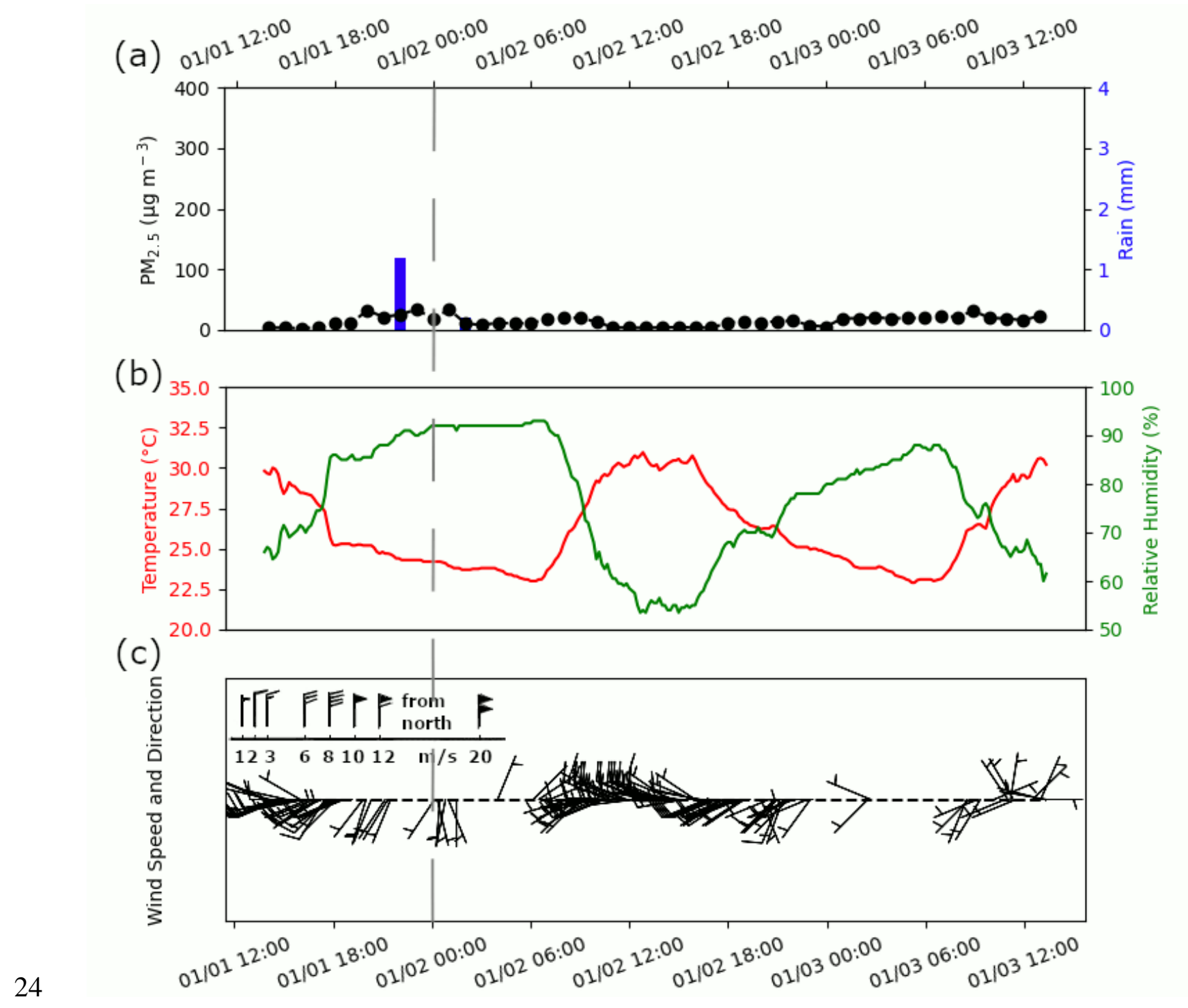

25 Figure S3: Same as Fig. S2 but for after the firework event. 


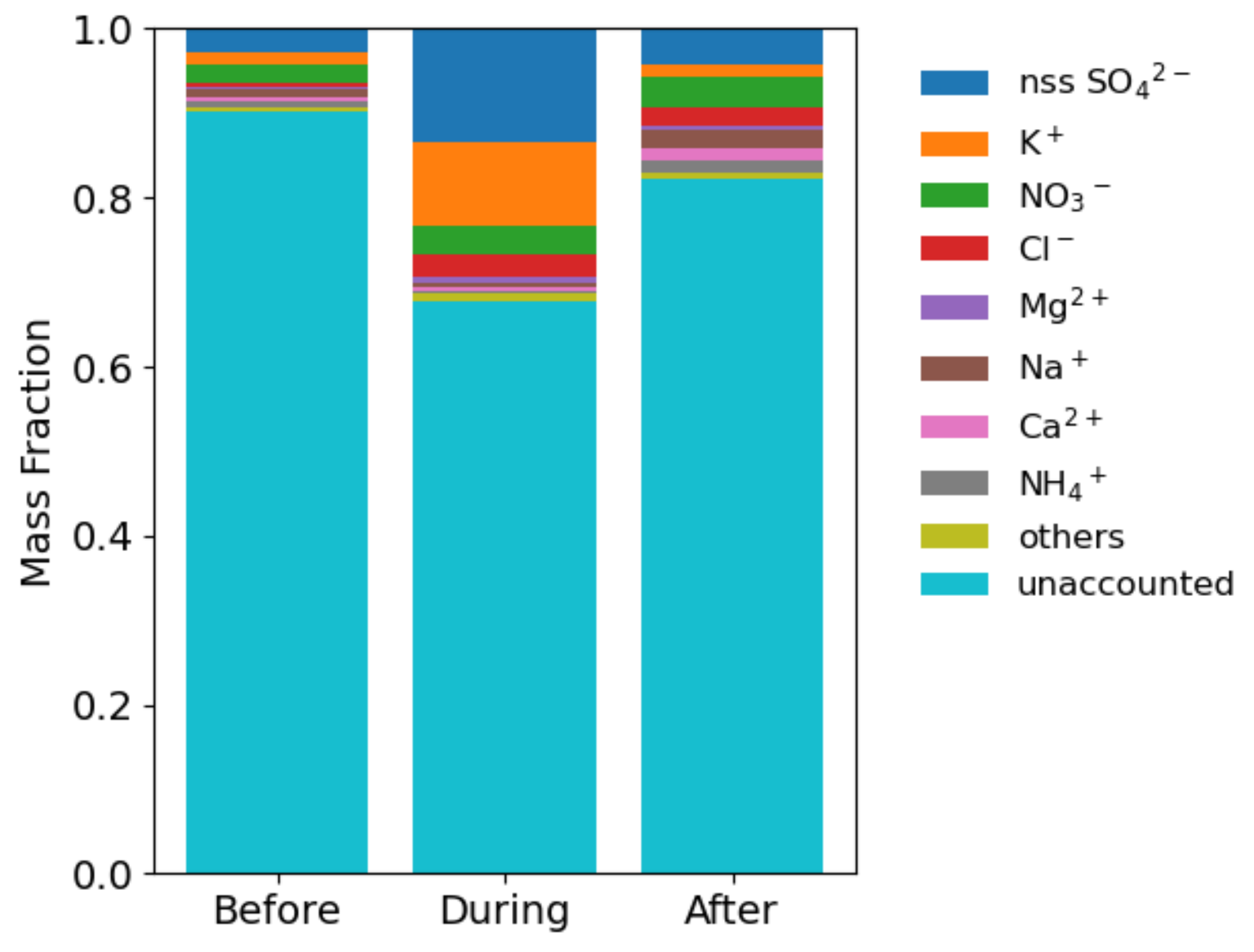

27 Figure S4: Mass fraction of water-soluble species $(0.056-3.2 \mu \mathrm{m})$ from 48-hour samples 28 collected on MOUDI samplers before, during, and after the firework event. Speciated 29 concentrations were compared to hourly $\mathrm{PM}_{2.5}$ concentrations as measured by a beta-attenuation 30 monitor that were averaged over 48 hours. 


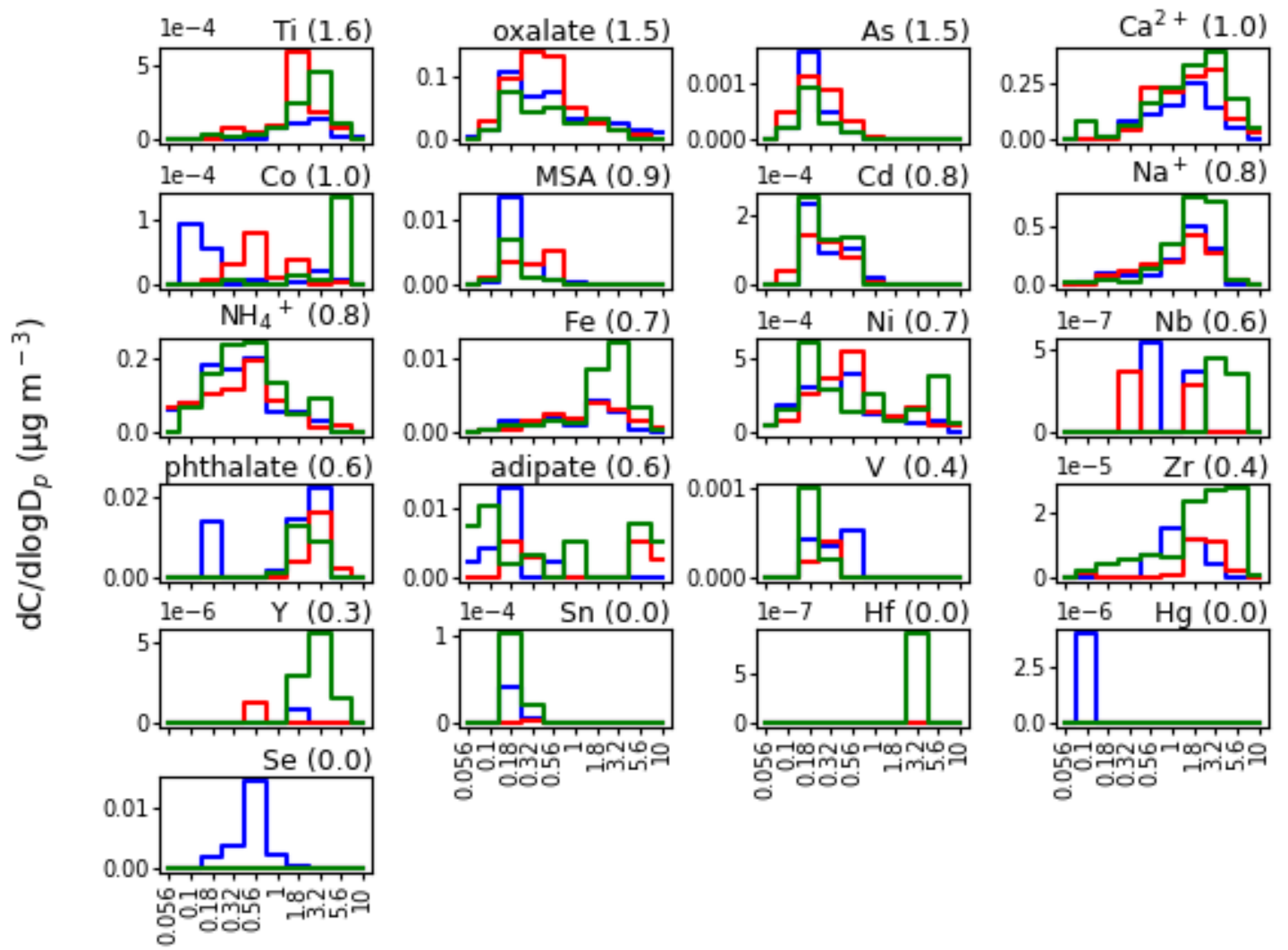

Cut-point Diameter $(\mu \mathrm{m})$

32 Figure S5: Speciated mass size distributions before (blue), during (red), and after (green) the 33 firework event. Next to species labels are bulk $(\geq 0.056 \mu \mathrm{m})$ mass concentration enrichment values 34 due to the firework event; species are shown here that exhibited enrichments $\leq 1.6$. 

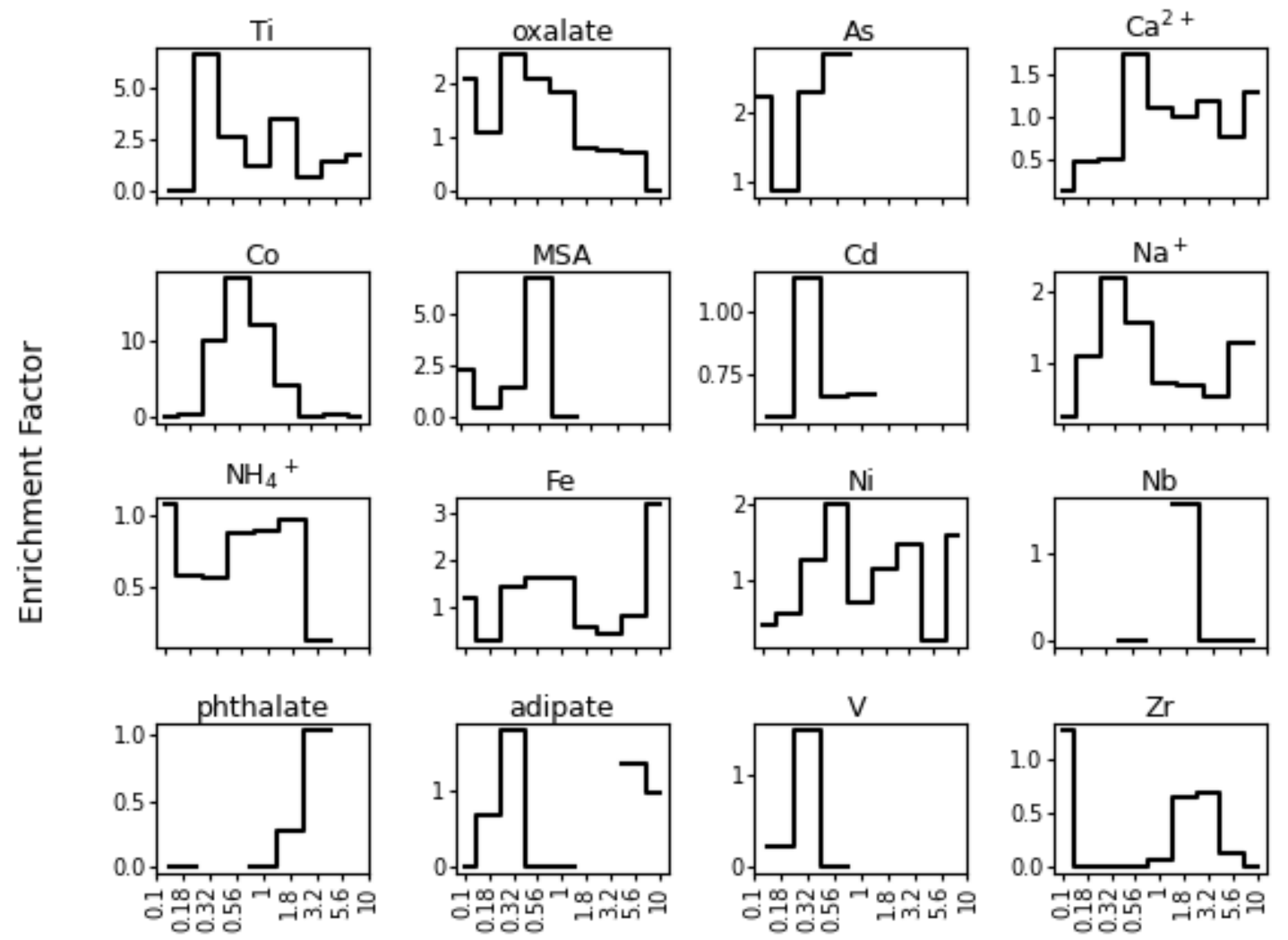

Figure S6: Size-resolved enrichments for individual firework tracer species in order of decreasing

37 total bulk mass concentration enrichment (species from Fig. S5). Cut-point diameters with no valid

38 data are left blank. 


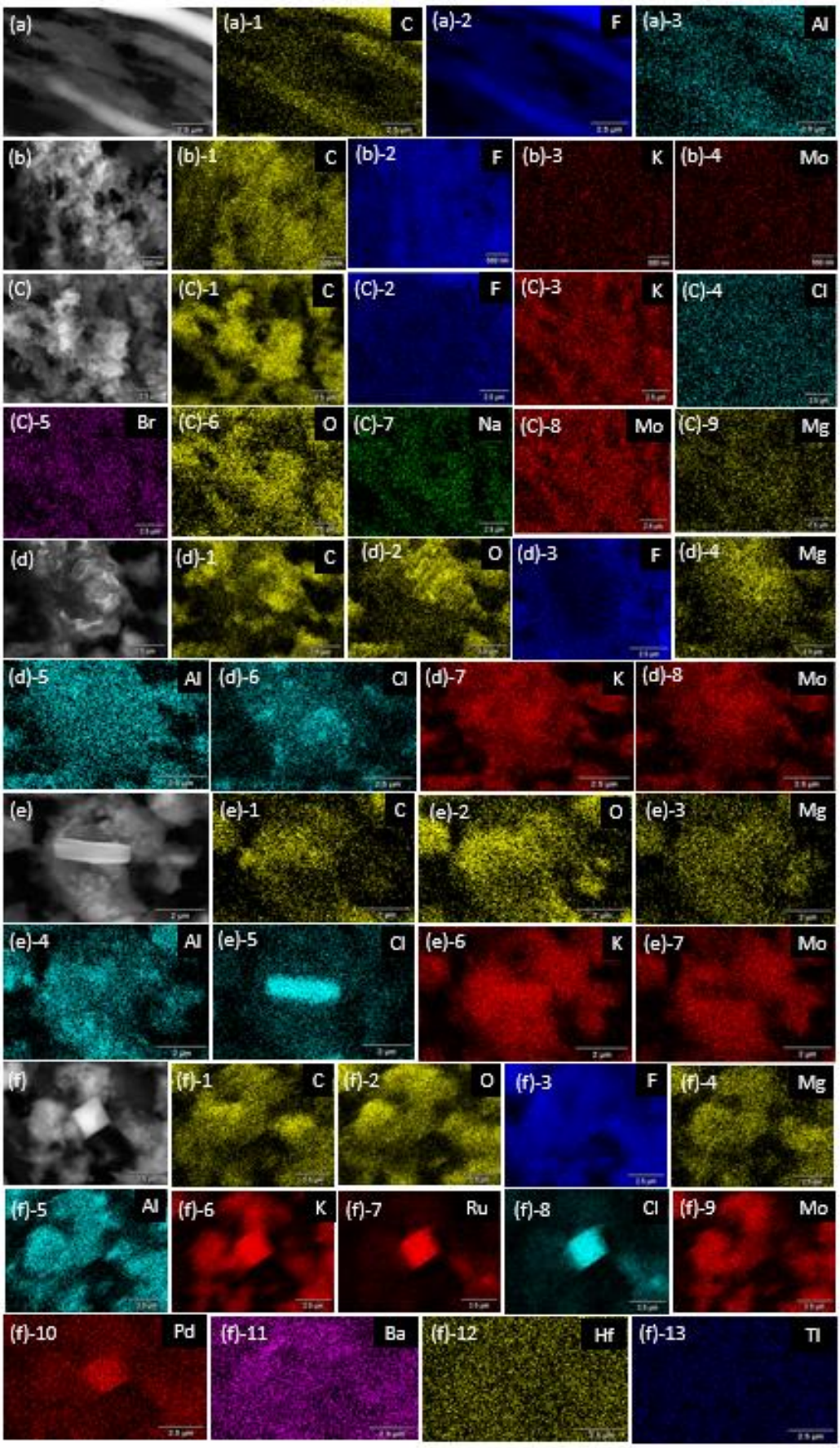

41 Figure S7: SEM images (gray-scale) and x-ray elemental maps from SEM-EDX of (a) a blank

42 PTFE (Teflon) substrate, and samples with firework influence in the following diameter ranges:

43 (b) $0.1-0.18 \mu \mathrm{m}$, (c) $0.18-0.32 \mu \mathrm{m}$, (d) $0.32-0.56 \mu \mathrm{m}$, and (e-f) $0.56-1.0 \mu \mathrm{m}$. The color 44 density of the elemental maps is related to the concentration for the particular element (upper 45 right of each map) in the x-ray maps relative to the backscattered electron image (gray-scale). 